\title{
Diagnóstico por Imagem na Instabilidade Metatarsofalângica ${ }^{(*)}$ Image Diagnosis for Metatarsophalangeal Joint Instability
}

\author{
Flávia Aiko Sakamoto ${ }^{(1)}$, Denise Tokeshi Amaral ${ }^{(1)}$, André Yui Aihara $^{(1)}$, Jamil Natour ${ }^{(2)}$, \\ Artur da Rocha Corrêa Fernandes ${ }^{(1)}$
}

\section{INTRODUÇÃO}

A instabilidade metatarsofalângica (MTF) é definida como um processo inflamatório agudo, subagudo, e menos comumente crônico das estruturas periarticulares que estabilizam uma ou mais articulações MTFs. O diagnóstico desta condição freqüentemente não é feito nem considerado; caso não tratado pode evoluir com enfraquecimento e/ou lesão da cápsula ou da placa plantar além de instabilidade articular, com subseqüente deformidade do dedo ${ }^{(1)}$.

A segunda articulação MTF é a mais acometida ${ }^{(2)}$, sendo o desvio geralmente medial, menos comumente lateral, podendo estar acompanhado de migração dorsal da falange proximal $^{(1)}$. O progresso de subluxação ou deslocamento do dedo pode ser rápido ou lento.

Existem fatores desencadeadores intrínsecos e extrínsecos do processo inflamatório inicial ${ }^{(3)}$. Os fatores intrínsecos incluem doença inflamatória articular como artrite reumatóide, doença do tecido conjuntivo e outras sinovites articulares que provocam a deterioração dos ligamentos colaterais e da cápsula articular, com subseqüente lesão ou ruptura da placa plantar. As causas extrínsecas compreendem o hálux valgo, o segundo osso metatársico longo (ou o primeiro curto) e a hipermobilidade do primeiro raio que podem predispor para a sinovite aguda, gerando distensão capsular e lesão da placa plantar. O desvio lateral do hálux também pode estar associado às forças que determinam hiper extensão da segunda articulação MTF, resultando na perda da estabilização da musculatura intrínseca. Essas condições combinadas predispõem a subluxação do segundo dedo, lesão ou ruptura da placa plantar com possível deslocamento da falange.

\section{ANATOMIA E BIOMECÂNICA}

A placa plantar é descrita como um espessamento da fibrocartilagem da cápsula articular metatarsofalângica na sua face plantar, firmemente aderida à base da falange proximal e apenas frouxamente fixada à cabeça metatarsiana. É composta por cartilagem tipo I, histologicamente idêntica ao do menisco do joelho. A placa plantar é a maior estrutura de fixação distal da fácia plantar, e possui fixações no ligamento metatarso transverso e ligamentos colaterais da articulação MTF. Também desempenha a função de inserções dos tendões interósseos e lumbricais. Inferiormente, a placa plantar tem uma depressão para a passagem do tendão flexor ${ }^{(2)}$.

A estabilidade da articulação MTF é devida à placa plantar, aos ligamentos colaterais, e à musculatura extrínseca e intrínseca do pé. Bhatia, Myerson e Curtis (1994), estudando a biomecânica da contenção do deslocamento dorsal da articulação MTF, demonstraram que há redução de $48 \%$ da força necessária para deslocá-la quando os ligamentos colaterais são seccionados, enquanto a redução é de $29 \%$ quando a placa plantar é seccionada ${ }^{(2)}$. No entanto, segundo Yu et al. (2002), a estabilização estática da articulação MTF é feita primariamente pela placa plantar e pelos ligamentos colaterais.

\section{ETIOPATOGENIA}

O fator principal para o desenvolvimento da subluxação ou deslocamento idiopático dos dedos dos pés é a inflamação progressiva da articulação MTF com subseqüente lesão e ruptura da placa plantar e/ou dos ligamentos colaterais ${ }^{(1)}$. Aproximadamente $25 \%$ de toda a carga no antepé

\footnotetext{
* Departamento de Diagnóstico por Imagem da Universidade Federal de São Paulo (DDI/Unifesp/EPM), São Paulo-SP, Brasil.

1. DDI/Unifesp/EPM, São Paulo-SP, Brasil.

2. Disciplina de Reumatologia da Unifesp/EPM, São Paulo-SP, Brasil.

Endereço para correspondência: Prof. Dr. Artur da Rocha Corrêa Fernandes. Departamento de Diagnóstico por Imagem da Universidade Federal de São Paulo (DDI/Unifesp/EPM), Rua Botucatu, 740, CEP 04023-900, São Paulo, SP, Brasil.
} 
centraliza-se no segundo dedo, pois, em razão de seu comprimento, faz parte dos dois eixos de força e equilíbrio do antepé durante a fase de impulsão da deambulação. Outro fator predisponente é o uso de sapatos de salto alto, que aumenta a carga no antepé e o mantém em posição de hiperextensão(1).

A hipermobilidade biomecânica também pode predispor para a alteração do padrão de carga do antepé. A pronação excessiva muda o eixo da inserção do tendão fibular longo na sua posição, estabilizador do primeiro raio durante a fase de carga do antepé na deambulação, causando a transferência da carga excessiva para as articulações MTF adjacentes. Similarmente, a insuficiência do primeiro raio causada por síndromes de hipermobilidade articular generalizada, como a síndrome de Ehlers-Danlos ou a síndrome de Marfan também pode causar instabilidade. Há ainda casos pós-cirúrgicos de correção de hálux valgo que provocam hipermobilidade ${ }^{(1)}$.

Coughlin (1993) identificou duas populações distintas de risco para desenvolver a instabilidade da segunda articulação MTF. O primeiro grupo consiste principalmente de mulheres sedentárias, com idade entre 50 e 70 anos (média de 60 anos). A grande proporção de mulheres idosas neste grupo é atribuída ao prevalente uso de sapatos de salto alto. O segundo grupo incide predominantemente em homens atletas de 25 a 64 anos, com idade média de 50 anos, a maioria apresentando o segundo metatarso comprido. A hipótese para este grupo foi que a atividade física repetitiva resulta em inflamação da segunda articulação MTF, eventualmente resultando em enfraquecimento das estruturas periarticulares que estabilizam o dedo. O autor entende que em ambas as teorias tanto a alteração estrutural quanto a disfunção biomecânica do primeiro raio contribuem para a instabilidade MTF. Entretanto, esta condição pode ocorrer na ausência destes fatores predisponente $^{\mathrm{s}(1)}$.

\section{QUADRO CLÍNICO}

Os pacientes com instabilidade MTF geralmente referem aumento da sensibilidade local na face plantar da base do dedo ${ }^{(1,3)}$, em alguns casos com sensação de deslocamento da $\operatorname{articulação~}^{(1)}$. A história clínica é comumente inespecífica, estando às vezes relacionada à atividade física acentuada, mudanças e/ou início de exercícios como corrida, tênis e basquetebol, ou ainda após traumas ${ }^{(1,2,4)}$. Inicialmente a dor é lancinante durante a palpação, localizada lateralmente na região central da placa plantar, e desproporcional à apresentação clínica que geralmente não demonstra deformidade, crepitação ou desalinhamento. Alguns referem agravo ao deambular com os pés descalços em superfície dura. Há alívio da dor à mobilização da articulação, particularmente durante a flexão plantar ${ }^{(1)}$. Em estágios tardios, pode haver dor intensa com conseqüente marcha antálgica, apoiada na região lateral do pé. Geralmente observa-se contratura de partes moles associada; o edema local, quando presente, pode ser limitado à articulação MTF ou comprometer todo o dedo, estando ou não associado a eritema. Tanto o edema quanto o eritema podem diminuir em determinadas fases da doença, mas a deformidade permanece ou evolui, podendo provocar a sobreposição do segundo dedo sobre o primeiro.

A síndrome da articulação calcâneo-cuboídea e a hipersolicitação da coluna lateral são manifestações secundárias que podem ocorrer e se tornar, posteriormente, mais importantes que a própria instabilidade MTF.

Como a apresentação típica se dá com dor vaga e não específica, os pacientes freqüentemente já foram submetidos a tratamentos clínicos e/ou cirúrgicos prévios sem obter êxito. Ocasionalmente, a inflamação da bursa intermetatársica pode irritar o nervo local e resultar em uma síndrome neurítica ou dor semelhante à do neuroma de Morton, motivo pelo qual a instabilidade MTF geralmente é confundida com esta entidade ${ }^{(1)}$. É importante ainda citar que as funções dos tendões flexores e extensores são minimamente ou não afetadas.

A instabilidade MTF é primariamente um diagnóstico de exclusão, requerendo uma história clínica e exame físico detalhados, não apresentando achados patognomônicos. Outras entidades podem ser a causa de metatarsalgia, tais como doença osteodegenerativa, necrose avascular, artrite reumatóide, fratura por estresse, disfunções neuromusculares e neuroma ${ }^{(1)}$.

\section{$\overline{\text { DIAGNÓSTICO CLÍNICO }}$}

O teste de estresse provocativo, também conhecido como teste de Lachman ou da gaveta, auxilia no diagnóstico da integridade da placa plantar. Neste teste é feita a estabilização da cabeça metatarsiana, enquanto a base da falange proximal é deslocada verticalmente no plano sagital. O deslocamento dorsal vertical de mais de $50 \%$ da altura da cabeça metatarsiana é considerada positiva para lesão ou ruptura. Esta manobra invariavelmente é acompanhada de dor ${ }^{(3)}$. 


\section{DIAGNÓSTICO POR IMAGEM}

Várias modalidades de imagem podem avaliar a instabilidade das articulações MTF. A radiografia é o método mais prático e essencial para detectar doenças sistêmicas associadas e definir o local acometido. As radiografias em perfil com carga e oblíqua indicam claramente a subluxação dorsal da falange proximal sobre a cabeça do metatarso. A incidência ântero-posterior com carga demonstra de forma indireta o desvio dorsal e transversal. O espaço da articulação MTF normal é de $2 \mathrm{~mm}$ a $3 \mathrm{~mm}$ e apresenta superfície articular congruente. $\mathrm{Na}$ subluxação dorsal ou deslocamento o espaço articular é obliterado pela sobreposição da base da falange proximal e a cabeça do metatarso (Figura 1). A incongruência do espaço articular é diagnosticada quando o dedo está desviado no plano sagital ou transversal. $\mathrm{Na}$ incidência ântero-posterior também se avalia o comprimento dos metatarsos que podem contribuir para o desenvolvimento ou progressão desta deformidade ${ }^{(1)}$. A hipertrofia cortical dos metatarsos pode estar presente e acreditase que indique sobrecarga anormal no antepé. A radiografia em perfil com o teste de estresse vertical pode ser usada para confirmar a instabilidade no plano sagital ${ }^{(1)}$.

Outros métodos de imagem podem ser solicitados quando não houver quadro clínico ou achados radiográficos claros, dentre eles a artrografia, a cintilografia e a ressonância magnética (RM). A artrografia com a injeção de $0,5 \mathrm{ml}$ a $1 \mathrm{ml}$ de contraste iodado na região dorsal da articulação MTF guiado por fluoroscopia pode avaliar a integridade da cápsula articular. Sua ruptura pode ser demonstrada pela opacificação da bainha do tendão flexor enquanto o extravasamento de contraste para a bursa intermetatársica é indicativo de ruptura do ligamento colateral ${ }^{(1,6)}$.

Embora não seja muito utilizado, o estudo cintilográfico ósseo de três fases com tecnésio ${ }^{99}$ pode demonstrar aumento da captação na articulação MTF em todas as fases, sendo mais intensa nas duas primeiras. Este padrão sugere mais um processo inflamatório local que um problema ósseo. A cintilografia óssea também pode identificar fraturas de estresse não diagnosticadas na radiografia convencional, com captação do radiofármaco em todas as fases, sendo maior na tardia (36 horas), com padrão linear no metatarso acometido, diferentemente da instabilidade MTF que envolve a área da articulação $\operatorname{MTF}^{(1,3)}$.

As manifestações da instabilidade MTF podem ser demonstradas pela RM de baixo ou alto campo. As seqüências necessárias são as ponderadas em T1 e gradiente "eco", sem e com saturação de gordura, realizados nos planos axial oblíquo, sagital e coronal. As seqüências FSE ou turbo "Spin-Eco" ponderadas em T2 com saturação de gordura, mais recentemente, tem se mostrado mais efetivas para esta avaliação. As imagens sagitais são obtidas com pulsos perpendiculares, programados paralelamente ao maior eixo dos metatarsos. As imagens coronais são obtidas através de cortes programados perpedicularmente ao maior eixo dos metatarsos. As seqüêencias axiais oblíquas são alinhadas com a face dorsal dos pés, com uma discreta inclinação lateral ${ }^{(1)}$ (Figura 2).

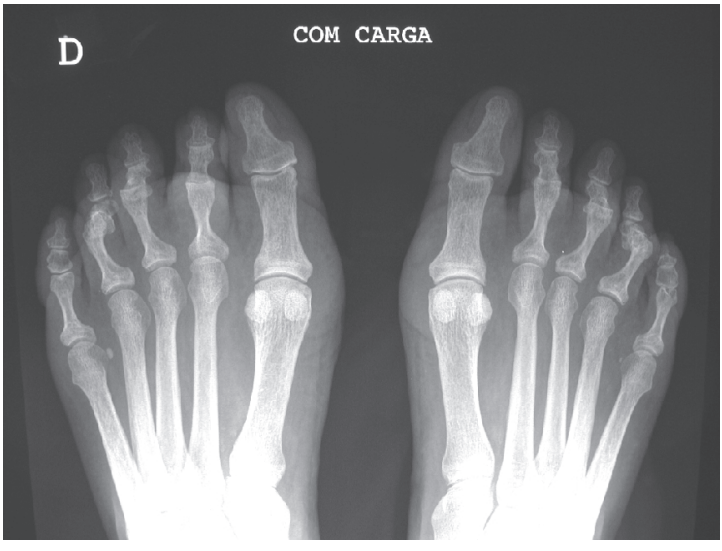

FIgURA 1- Radiografia ântero-posterior dos pés, evidenciando distensão de partes moles periarticulares da II MTF direita, com obliteração do espaço articular sugerindo deslocamento articular.

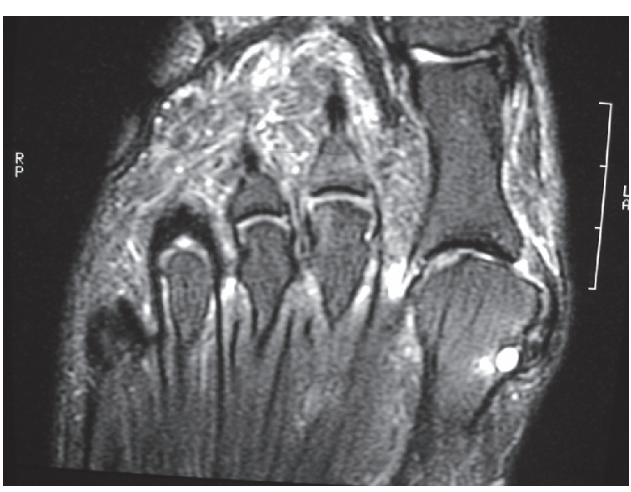

Figura 2- RM do antepé no plano axial, mostrando o II metatarso longo de um paciente com instabilidade MTF, evidenciando irregularidade e heterogeneidade do sinal dos ligamentos colaterais e cápsula. 
A placa plantar e suas estruturas associadas são mais bem observadas nas seqüências T1, GE e especialmente nas seqüências FSE ou turbo "Spin-Eco" ponderadas em T2 com saturação de gordura. Nas imagens ponderadas em T1, a placa plantar é vista como uma estrutura regular de baixo sinal, localizada inferiormente à cabeça metatársica e a base da falange proximal. É difícil diferenciá-la do tendão flexor nas imagens ponderadas em T1; as imagens em GE podem auxiliar, pois a placa plantar apresenta sinal discretamente maior que o tendão que passa logo inferiormente ${ }^{(1)}$.

A ruptura da placa plantar é demonstrada com áreas de hipersinal na placa, que apresenta áreas de descontinuidade. A área de ruptura tem intensidade de sinal semelhante à sinóvia e ao líquido articular localizado adjacente à cabeça do metatársica (Figuras 3 e 4). Sinovite na bainha do tendão flexor e distensão da cápsula articular da MTF são achados associados comuns à ruptura da placa plantar.

\section{TRATAMENTO}

As alternativas terapêuticas dependem da intensidade da dor, da deformidade e das limitações do paciente. O objetivo do tratamento conservador é aliviar os sintomas e prevenir a progressão da deformidade ${ }^{(1,3)}$. Muitos pacientes em estágio precoce apresentam alívio dos sintomas em 70\% a 90\% após alguns dias de tratamento, com retorno da função articular. Porém, em estágios tardios, raramente respondem à terapia conservadora. O tratamento cirúrgico é indicado se houver progressão da deformidade e/ou falha após o tratamento conservador. São vários os procedimentos cirúrgicos existentes para a correção da deformidade, com grande divergência quanto à técnica a ser aplicada. O objetivo de todos é aliviar a contratura periarticular e restabelecer o alinhamento do dedo, além de reestruturar a função da placa plantar e liberar as estruturas contraídas na
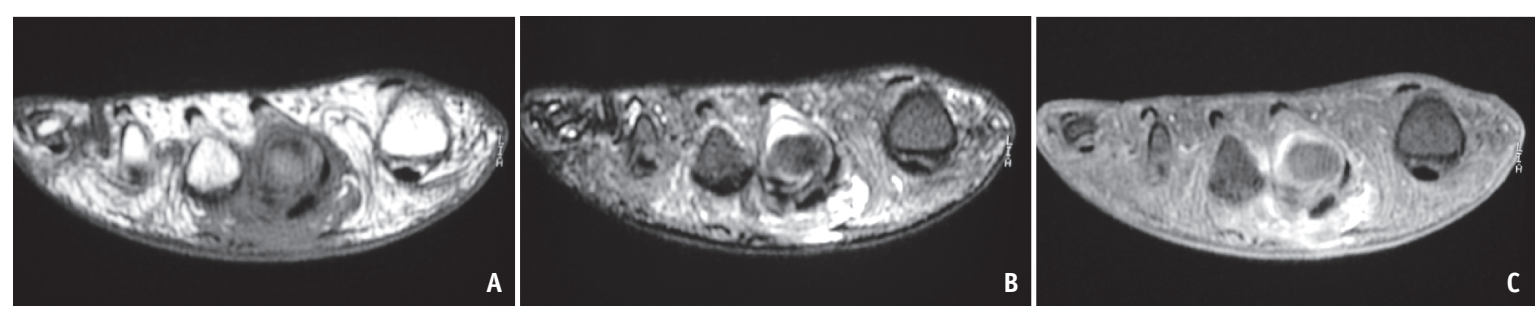

Figura 3-RM do antepé no plano coronal, evidenciando lesão da placa plantar do II dedo, caracterizado por heterogeneidade e irregularidade da placa plantar nas seqüências ponderadas em T1 (a), T2 (b) e após contraste endovenoso (c), demonstrando edema de partes moles adjacente caracterizado por hipossinal em T1 e hiperssinal em T2 e realce após contraste associado ao processo inflamatório.

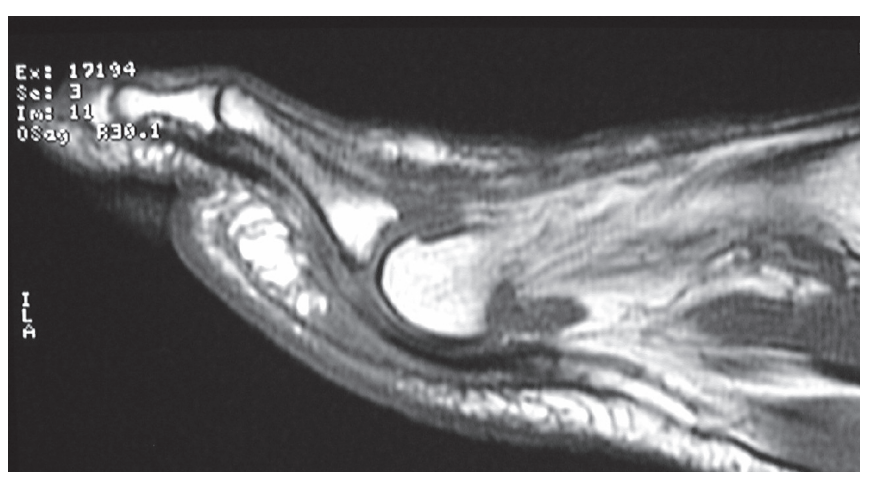

FiguRA 4a- RM do ante pé no plano sagital evidenciando lesão da placa plantar do II dedo caracterizado por heterogeneidade e irregularidade da placa plantar na seqüência ponderadas em T1.

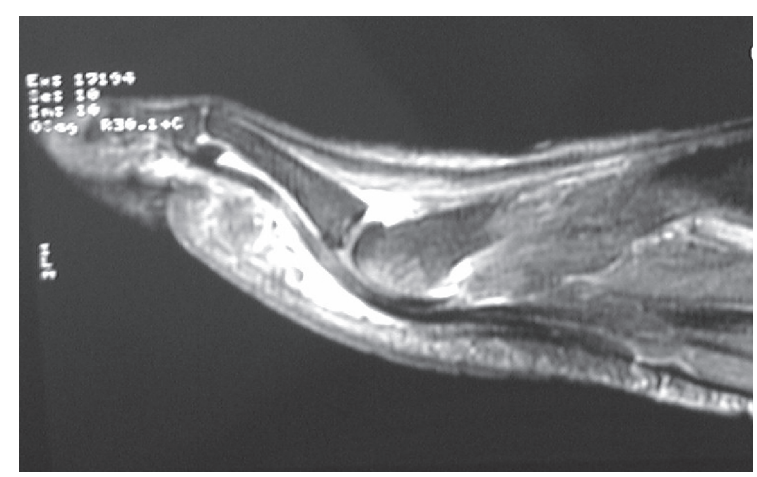

Figura 4b- RM do ante pé no plano sagital, evidenciando lesão da placa plantar do II dedo caracterizado por heterogeneidade e irregularidade da placa plantar e realce pós contraste nas seqüências ponderadas em T1, com saturação de gordura nas partes moles adjacentes à mesma. 
região dorsal da articulação ${ }^{(1)}$. Essas técnicas variam desde uma sinovectomia e correção de partes moles até a osteotomia do metatarso e da base da falange distal. A transferência do tendão flexor longo dos dedos para a superfície extensora da falange proximal tem sido descrita como uma boa opção de correção da instabilidade MTF.

\section{CONCLUSÃO}

A instabilidade MTF é uma entidade clínica comum, freqüentemente subdiagnosticada. Caso não seja tratada adequadamente pode evoluir com enfraquecimento e lesão da cápsula ou da placa plantar e instabilidade articular, com subseqüente deformidade do dedo. Seu diagnóstico é de

\section{REFERÊNCIAS}

1. Fortin PT, Myerson MS: Second metatarsophalangeal joint instability. Foot Ankle Int 16:306-13, 1995.

2. Yu GV, Judge MS, Hudson JR, et al: Predislocation syndrome Progressive subluxation/dislocation of the lesser metatarsophalangeal joint. J Am Podiatr Med Assoc 92:182-99, 2002.

3. Mendicino RW, Statler TK, Saltrick KR, et al: Predislocation syndrome: a review and retrospective analysis of eight patients. J Foot Ankle Surg 40:214-24, 2001. exclusão e necessita de avaliação detalhada na anamnese e exame físico. A utilização dos métodos de imagem pode auxiliar no diagnóstico preciso ao descartar outras doenças que acometem o antepé, permitindo a antecipação do diagnóstico e evitando a necessidade de terapêutica mais agressiva. Várias modalidades de imagem podem avaliar a instabilidade das articulações MTF. A radiografia é o método mais prático para detectar doenças sistêmicas associadas e definir o local acometido. Quando há dificuldade de caracterização dos achados radiográficos e o quadro clínico é sugestivo de instabilidade MTF, a ressonância magnética pode demonstrar alterações mais precoces e fornecer informações mais detalhadas das estruturas que estabilizam a articulação MTF.

4. Stephenson KA, Beck TL, Richardson EG: Plantar dislocation of the metatarsophalangeal joint: case report. Foot Ankle Int 15:446-9, 1994.

5. Johnston RB, Smith J, Daniels T: Plantar dislocation of the metatarsophalangeal joint: case report. Foot Ankle Int 15:276-82, 1994.

6. Yao L, Do HM, Cracchiolo A, et al: Plantar plate of the foot: Findings on conventional arthrography and MR imaging. AJR 163:641-4, 1994. 